\title{
The Effect of Upper Airway Surgery on Continuous Positive Airway Pressure Levels and Adherence: A Systematic Review and Meta-Analysis
}

\author{
Christopher M. Ayers Shivangi Lohia Shaun A. Nguyen \\ M. Boyd Gillespie
}

Department of Otolaryngology - Head and Neck Surgery, Medical University of South

Carolina, Charleston, S.C., USA

\section{Key Words}

Upper airway surgery · Sleep surgery · Obstructive sleep apnea · Continuous positive airway pressure $\cdot$ Meta-analysis

\begin{abstract}
Background /Aims: The aim of this study was to determine the effect of upper airway surgery (UAS) on continuous positive airway pressure (CPAP). A secondary objective was to determine if a decrease in CPAP from UAS increases CPAP adherence. Methods: Studies were eligible for inclusion if a CPAP titration was performed both prior and following UAS in patients with obstructive sleep apnea (OSA). Studies that compared adherence to CPAP before and after UAS were included to evaluate the secondary objective. Results: A total of 11 articles involving 323 patients were included in the review. The results show that there was a mean reduction in CPAP of $1.40 \mathrm{~cm} \mathrm{H}_{2} \mathrm{O}(95 \% \mathrm{CI}-2.08$ to -0.73$)$. Four of the 11 papers, with a total of 80 patients, evaluated CPAP adherence and found a significant 0.62-hour improvement on average $(95 \%$ CI 0.22-1.01). Conclusion: Due to high levels of nonadherence, surgical intervention will play a role even in patients who are unlikely to be fully cured by surgery. UAS decreases the apneahypopnea index and modestly reduces CPAP while improving CPAP adherence in the majority of patients. The evidence suggests that UAS may have an adjunctive role in the management of OSA.


Ayers et al.: The Effect of Upper Airway Surgery on Continuous Positive Airway Pressure Levels and Adherence: A Systematic Review and Meta-Analysis

\section{Introduction}

Obstructive sleep apnea (OSA) is a common disorder in which loss of tone of the upper airway results in airway collapse with intermittent obstruction of ventilation during sleep. The apnea-hypopnea index (AHI) is currently the most objective and thoroughly analyzed parameter to determine the severity of OSA. In addition, the AHI offers the best measure of OSA in relation to its clinical manifestations, with a higher AHI associated with more severe daytime sleepiness, fatigue, unrefreshing sleep, and impaired memory and concentration. Unfortunately, the morbidity of OSA does not stop with the sleep-related clinical manifestations. Additional morbidities linked to OSA include hypertension, coronary artery disease, arrhythmias, heart failure, and stroke $[1,2]$. The burden of OSA is evident when one considers that an estimated $24 \%$ of men and $9 \%$ of women in the US have sleep parameters consistent with OSA with an AHI $\geq 5$ [3].

Currently, the first-line treatment for moderate to severe OSA is continuous positive airway pressure (CPAP) [4]. Studies suggest that there is a significant reduction in daytime sleepiness and increase in daily functioning with the use of CPAP [5, 6]. A minimum of $4 \mathrm{~h}$ of nightly CPAP is recommended [5]. Unfortunately, adherence to CPAP therapy has long been an issue in treating sleep apnea [7-9]. It is estimated that up to $15 \%$ of patients discontinue CPAP after their first-night trial [10]. Other recent studies demonstrate that even with intensive support, education, and follow-up, CPAP use drops to $80 \%$ within the first 10 months [11]. Reasons for poor adherence include nasal resistance and congestion, sinus pressure, claustrophobia, air leaks, feelings of suffocation, and inability to change sleep routine. Many of these complaints are associated with the level of CPAP, with higher pressures associated with reduced CPAP adherence [9].

Although surgical modification of the upper airway has been described for many years [12], the role of upper airway surgery (UAS) for OSA continues to be a subject of debate [1315]. This is largely secondary to a scarcity of high-level evidence due to lack of randomization, lack of gold-standard surgical procedures, and differences in treatment groups. In general, particularly in cases of severe OSA, UAS may reduce the AHI and improve clinical symptoms but rarely normalizes the AHI. Therefore, surgery has been generally reserved for patients who have failed to use CPAP at recommended levels. UAS, however, may also have a role as an adjunct to improve CPAP use in select patients, especially those who have difficulty tolerating high CPAPs. The present systematic review and meta-analysis seeks to test the null hypothesis that UAS does not change CPAP titration. In addition, the study will test the secondary hypothesis that UAS has no effect on subsequent CPAP adherence.

\section{Methods}

Search Methods

Two independent searches of PubMed, Medline, and the Cochrane Library were performed in April 2013 using the following search terms: 'obstructive sleep apnea', 'upper airway', 'surgery', 'sleep disordered breathing', and 'continuous positive airway pressure'. All articles were considered regardless of language. In addition, the reference lists of articles obtained were reviewed for any articles missed in the search, and authors of published guidelines, experts in the field, and study sponsors were contacted to assess for unpublished studies.

\section{Inclusion/Exclusion Criteria}

Studies included in the review were any randomized controlled trials (RCTs), nonrandomized prospective trials, and retrospective studies of a surgical intervention for OSA in which CPAP titration was performed before and after the surgical intervention. Single- and double-blind studies were both included, as were appropriate crossover trials. The following surgical treatments were included: septoplasty, inferior 
Fig. 1. Literature search strategy.

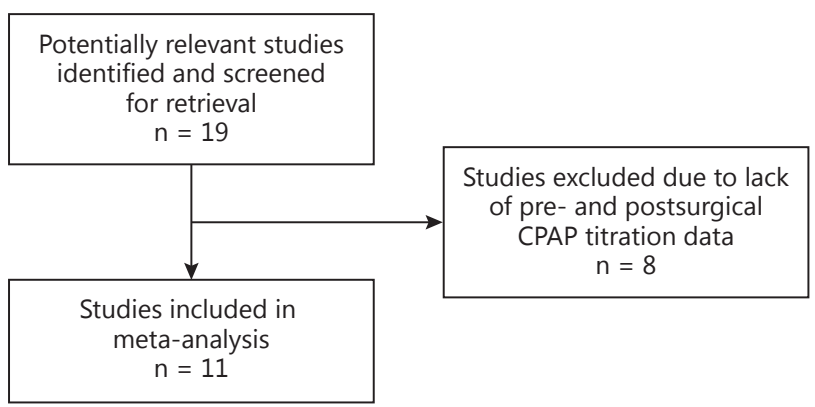

turbinate reduction, nasal valve repair, upper airway radiofrequency reduction, tonsillectomy, and uvulopalatopharyngoplasty (UPPP). Studies were excluded if they did not provide titrated CPAPs prior to and after surgical intervention. Any differences in opinion regarding the inclusion of a particular study were resolved by discussion among the authors. Figure 1 outlines the findings of the literature search.

Data Extraction and Analysis

Data from included studies were extracted using standardized forms and checked by a second author. The CPAP results were recorded as absolute values and/or changes from baseline using the last time point available for each study. Data reported in graphical plots were not extracted for meta-analysis unless numeral points were available and verifiable. Attempts were made to obtain further or complete details of published results from authors in the event of missing or incomplete data.

A meta-analysis of selected studies with a continuous measure [comparison of means and standard deviations (SD) between control and treatment groups] was performed with Cochrane Review Manager (RevMan) version 5.2 (The Nordic Cochrane Centre, The Cochrane Collaboration, 2011, Copenhagen, Denmark). Both the fixed-effects model and the random-effects model were used in this study. Under the fixed-effects model, it was assumed that all studies come from a common population and that the effect size [standardized mean difference (SMD)] was not significantly different between the different trials. This assumption was tested by the heterogeneity test or $\mathrm{I}^{2}$ statistic. If this test yielded a low p value $(\mathrm{p}<0.05)$, then the fixed-effects model was invalid. In this case, the random-effects model was more appropriate, in which both the random variation within the studies and the variation between the different studies was incorporated. For this study, the mean difference (MD) was calculated for all outcomes. The MD is a standard statistic that measures the absolute difference between the mean value in two groups in a clinical trial. It estimates the amount by which the experimental intervention changes the outcome on average compared with the control. It can be used as a summary statistic in a meta-analysis when outcome measurements in all studies are made on the same scale. A 95\% confidence interval (CI) was calculated for each MD.

For this study, the null hypothesis was that there was no difference between pretreatment and posttreatment with respect to pooled CPAP and CPAP use as outcome measures. Effect sizes were calculated using MDs with corresponding $95 \%$ CIs. If the value of 0 was not within the $95 \%$ CI range, then the MD was statistically significant at the $5 \%$ level $(\mathrm{p}<0.05)$.

\section{Results}

The results of the systematic review are listed in table 1 . There were 19 studies found in the literature that evaluated patients on CPAP with polysomnography both before and after surgical interventions of the upper airway. Eight studies were excluded due to lack of a comparison of pre- and postoperative CPAPs in patients after UAS. Of the 11 studies that met the inclusion criteria, 5 were retrospective [8, 16-19], 4 were prospective [20-23], and 2 were RCTs [24, 25]. UAS performed in the studies included nasal valve repair, radiofrequency 
Ayers et al.: The Effect of Upper Airway Surgery on Continuous Positive Airway Pressure Levels and Adherence: A Systematic Review and Meta-Analysis

Table 1. Description of studies included in the meta-analysis

\begin{tabular}{|c|c|c|c|c|c|c|}
\hline First author [ref.], year & Study & $\begin{array}{l}\text { Patients, } \\
\mathrm{n}\end{array}$ & $\begin{array}{l}\text { Mean age (SD), } \\
\text { years }\end{array}$ & $\begin{array}{l}\text { Mean BMI } \\
\text { (SD) }\end{array}$ & $\begin{array}{l}\text { Mean AHI } \\
\text { (SD) }\end{array}$ & Intervention (n) \\
\hline Bertoletti [21], 2009 & prospective & 21 & $49.5(11.2)$ & $31.4(3.2)$ & $41.1(5.8)$ & Pillar palatal implants (21) \\
\hline Friedman [16], 2009 & retrospective & 52 & $43.1(9.1)$ & $31.2(5.0)$ & $63.2(22.0)$ & multilevel UAS \\
\hline Gillespie [24], 2011 & $\mathrm{RCT}$ & 26 & $52.3(10.3)$ & $34.7(5.0)$ & $42(21)$ & Pillar palatal implants (26) \\
\hline Khan [17], 2009 & retrospective & 27 & $42.1(13.9)$ & $34.9(7.2)$ & $62.0(35.4)$ & UPPP (27) \\
\hline Nakata [19], 2005 & prospective & 5 & $54.2(9.2)$ & $27.0(3.9)$ & $55.9(18.2)$ & $\begin{array}{l}\text { submucous resection of the nasal } \\
\text { septum +/- inferior tubinectomy }\end{array}$ \\
\hline Mortimore [22], 1996 & prospective & 17 & $\begin{array}{l}\mathrm{m}: 49(13.0) \\
\mathrm{f}: 44(5.0)\end{array}$ & $\begin{array}{l}\mathrm{m}: 30(7.1) \\
\mathrm{f}: 26.5(5.0)\end{array}$ & n.r. & UPPP \\
\hline Schonhofer [26], 2003 & RCT & 38 & $55.4(11.4)$ & $35.3(5.6)$ & $17.1(18.3)$ & nasal valve dilation (38) \\
\hline $\operatorname{Lin}[18], 2008$ & retrospective & 12 & n.r. & $34.14(4.7)$ & $65.15(49.2)$ & $\begin{array}{l}\text { UPPP (5); Pillar (1); UPPP, Genio, } \\
\text { Hyoid (6); UPPP, Hyoid, Repose (3); } \\
\text { UPPP, Genio (1) }\end{array}$ \\
\hline Sufioglu [23], 2012 & prospective & 28 & $53(9.6)$ & $30.3(4.1)$ & $32.5(22.6)$ & $\begin{array}{l}\text { septoplasty (3); septorhinoplasty (2); } \\
\text { septoplasty, RFA (18); ESS, } \\
\text { septoplasty, RFA (4); RFA (4) }\end{array}$ \\
\hline Zonato [8], 2006 & retrospective & 17 & $49(9)$ & $30(4)$ & $38(19)$ & $\begin{array}{l}\text { tonsillectomy (1); septoplasty (1); } \\
\text { septoplasty, tonsillectomy (2); } \\
\text { septoplasty, tonsillectomy, turbinate } \\
\text { diathermy (1); septoplasty, turbinate } \\
\text { diathermy (2); septoplasty, } \\
\text { turbinectomy (2); RFA (8) }\end{array}$ \\
\hline Nakata [20], 2006 & retrospective & 6 & $33.2(6.8)$ & $30.7(6.0)$ & $69.0(28.4)$ & Tonsillectomy \\
\hline
\end{tabular}

n.r. = Not reported; Genio = genioglossus advancement; Hyoid = hyoid myotomy and advancement; Repose = repose tongue suspension; RFA = radiofrequency ablation of the inferior turbinates; ESS = endoscopic sinus surgery.

ablation to the palate, turbinate reduction, septoplasty, Pillar implants, tonsillectomy, and UPPP. One study looked at radiofrequency ablation alone, 1 looked at tonsillectomy alone, 1 looked at nasal valve repair alone, whereas 2 looked at Pillar implants alone, and 2 looked at UPPP alone. The remaining studies looked at any combination of UAS.

In total, there were 323 patients evaluated of which $216(67 \%)$ were male and $44(14 \%)$ were female with $63(19 \%)$ of unknown gender. The mean age of the patient population was 47.4 years (range 12-71). The mean body mass index of the patient population was 32.8. Of these 323 patients, some were deemed surgically cured, and a small portion was lost to follow-up. Therefore, 249 (77\%) underwent CPAP titration prior to and following surgical intervention. Ten of the 11 studies (91\%) demonstrated a significant reduction in CPAP after UAS. The mean reduction in CPAP for all studies was $1.40 \mathrm{~cm} \mathrm{H}_{2} \mathrm{O}$ with a $95 \% \mathrm{CI}$ of -2.08 to -0.73 , shown in figure 2. Average presurgical CPAP was $10.8 \mathrm{~cm} \mathrm{H}_{2} \mathrm{O}$ and postsurgical CPAP was $9.4 \mathrm{~cm} \mathrm{H}_{2} \mathrm{O}$. A total of 76 patients did not undergo postoperative polysomnography and, therefore, were not included in the analysis. Of these, 23 patients reported resolution of symptoms with improvement in daytime sleepiness and refused to undergo repeat study.

Four studies evaluated CPAP adherence in a control and posttreatment group, or preoperative and postoperative use within the same group [18, 21, 24, 25]. Overall, 80 patients still requiring CPAP after surgery were evaluated after Pillar implants $(n=47)$, UPPP alone or in 
Ayers et al.: The Effect of Upper Airway Surgery on Continuous Positive Airway Pressure Levels and Adherence: A Systematic Review and Meta-Analysis

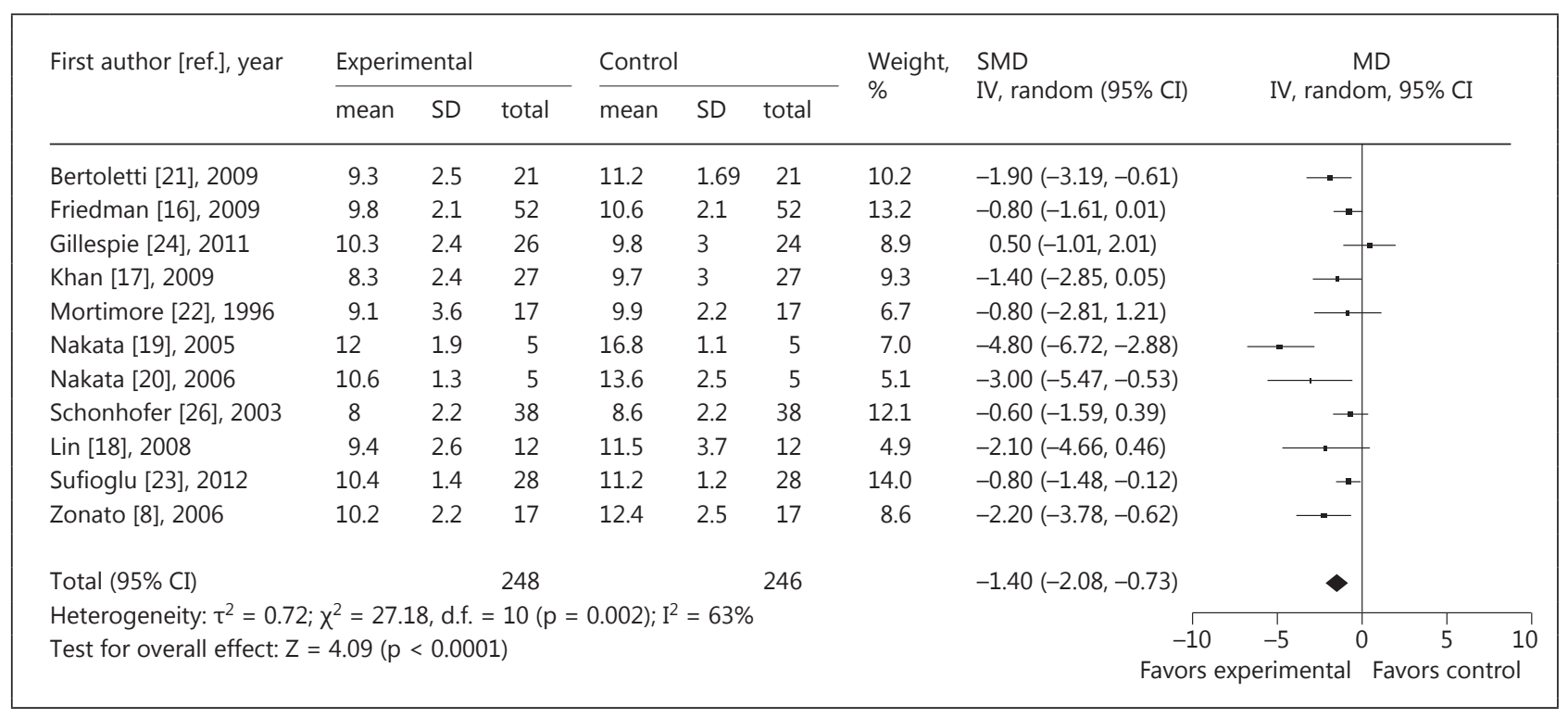

Fig. 2. Changes in CPAP after UAS.

\begin{tabular}{|c|c|c|c|c|c|c|c|c|c|c|c|c|}
\hline \multirow{3}{*}{$\begin{array}{l}\text { First author [ref.], year } \\
\text { Bertoletti [21], } 2009\end{array}$} & \multicolumn{3}{|c|}{ Experimental } & \multicolumn{3}{|c|}{ Control } & \multirow{3}{*}{$\begin{array}{l}\text { Weight, } \\
\%\end{array}$} & \multirow{3}{*}{$\begin{array}{l}\text { MD } \\
\text { IV, fixed }(95 \% \text { CI }) \\
0.60(0.14,1.06)\end{array}$} & \multirow{2}{*}{\multicolumn{4}{|c|}{$\begin{array}{l}\text { MD } \\
\text { IV, fixed, } 95 \% \text { CI }\end{array}$}} \\
\hline & \multirow{2}{*}{$\begin{array}{l}\text { mean } \\
6.36\end{array}$} & \multirow{2}{*}{$\begin{array}{l}\text { SD } \\
0.6\end{array}$} & \multirow{2}{*}{$\begin{array}{l}\text { total } \\
21\end{array}$} & \multirow{2}{*}{$\begin{array}{l}\text { mean } \\
5.76\end{array}$} & \multirow{2}{*}{$\begin{array}{l}\text { SD } \\
0.9\end{array}$} & \multirow{2}{*}{$\begin{array}{l}\text { total } \\
21\end{array}$} & & & & & & \\
\hline & & & & & & & & & & & $\mathbf{-}$ & \\
\hline Gillespie [24], 2011 & 6 & 2.4 & 26 & 6 & 2.5 & 26 & 8.8 & $0.00(-1.33,1.33)$ & & & & \\
\hline Lin [18], 2008 & 5.97 & 1.43 & 16 & 3.98 & 2.48 & 16 & 7.9 & $1.99(0.59,3.39)$ & & & & \\
\hline Powell [25], 2001 & 5.97 & 1.43 & 17 & 5.76 & 2.08 & 17 & 10.8 & $0.21(-0.99,1.41)$ & & & & \\
\hline Total $(95 \% \mathrm{CI})$ & & & 80 & & & 80 & 100.0 & $0.62(0.22,1.01)$ & & & 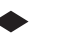 & \\
\hline \multicolumn{7}{|c|}{ Heterogeneity: $x^{2}=4.95$, d.f. $=3(p=0.18) ; I^{2}=39 \%$} & & -4 & & & 2 & 4 \\
\hline \multicolumn{7}{|c|}{ Test for overall effect: $Z=3.06(p=0.002)$} & \multicolumn{6}{|c|}{ Favors experimental Favors control } \\
\hline
\end{tabular}

Fig. 3. Changes in CPAP use (hours) after UAS.

combination with a multilevel procedure $(n=16)$, or inferior turbinate reduction $(n=17)$. Two of the studies demonstrated that UAS resulted in a significant improvement in CPAP compliance, while the other 2 either showed no difference or only a slight improvement. Figure 3 demonstrates that postoperative compliance to CPAP was increased by $0.62 \mathrm{~h}$ with a 95\% CI of 0.22-1.01 using the fixed-effects model. It must be noted that the majority of these patients underwent palatal implants alone, which has not been shown in the past to significantly reduce the $\mathrm{AHI}$.

Only 3 studies discussed surgical complications [8, 20,24]. Out of these, none observed major complications. Four patients undergoing Pillar implants experienced bleeding after placement, requiring application of silver nitrate or suture ligature. One patient experienced a post-tonsillectomy bleed requiring operative cauterization, and another experienced intranasal synechia after septoplasty and turbinectomy resulting in the need for scar band removal in the operating room. 


\section{Discussion}

CPAP is the most well-studied and effective treatment for the majority of patients with moderate to severe OSA. The role of UAS in the management of OSA remains controversial as most studies are limited by small samples sizes, surgeon differences, and subjective endpoints. Nevertheless, many patients fail to remain adherent to CPAP therapy over time. Typical reasons for noncompliance include poor fit, nasal congestion, sinus/nasal pressure, air leaks, and claustrophobia [27]. This represents a unique subset of patients who may benefit from surgical intervention in order to improve CPAP compliance.

Traditionally, surgical success in patients with OSA has been defined either by a reduction of the AHI by $50 \%$ with an overall AHI below 20, or elimination of the need for CPAP altogether. Unfortunately, reducing the AHI by $50 \%$ may not eliminate the need for CPAP in many cases. In this meta-analysis, the data cumulatively suggest that there is a reduction in CPAP as a result of UAS. In fact, only 1 study [24] failed to demonstrate a significant reduction in CPAP compared to placebo after surgery due to the observation that both the implants and the sham procedure reduced CPAP. In that study, the authors considered the possibility that the sham procedure, which involved tunneling a Pillar handpiece device in three soft-palate locations, created enough palatal stiffening to likewise lower CPAP.

The second goal of the study was to determine the effect of UAS on CPAP adherence due to pressure reduction or other mechanical changes. Two of the studies demonstrated that UAS resulted in a significant improvement in CPAP compliance, while the other 2 studies either showed no difference or only a slight improvement. Overall, the data suggest a modest significant increase in the use of CPAP after UAS. Unfortunately, the majority of our CPAP data comes from palatal implants alone, thereby making it difficult to extrapolate to other procedures.

The present review rejects each null hypothesis by demonstrating that there is a significant reduction in CPAP after UAS and that there is an increase in CPAP compliance after UAS.

There are significant limitations to this review given the paucity of high-level evidence from the studies reviewed. Firstly, only 2 studies were RCTs, and each study contained anywhere from a single UAS to multisite procedures, making it difficult to identify procedures that are likely to be most effective. Although the overall reduction in CPAP was modest, it would be helpful to have more patient-specific data to determine if CPAP reduction correlated with increased CPAP use after UAS. The present data did not allow this analysis. Secondly, it is important to note the heterogeneity of the UAS being performed. Currently, there is the perception in sleep medicine literature that surgical modification of the upper airway worsens CPAP adherence and effectiveness. Sleep specialists often lump sleep surgery together. The present review seeks to take a global look at surgical modification of the upper airway in patients that continue to need CPAP, and it shows that surgical modification does not worsen CPAP effectiveness and in fact reduces CPAP to a modest degree. Therefore, the review illustrates that there are a variety of upper airway surgical modifications that can be chosen in consultation between the surgeon and the patient, are unlikely to worsen CPAP effectiveness, and indeed may make it more effective.

\section{Conclusion}

CPAP remains the mainstay of treatment of moderate to severe OSA, but due to high levels of nonadherence, surgical intervention will play a role even in patients who are unlikely to be fully cured by surgery. In most cases, the AHI was decreased and CPAPs were lowered after UAS. Additional study is necessary to determine if CPAP adherence improved as a result of the lower CPAP or due to the fact that surgery was tried and was not completely successful. 
Ayers et al.: The Effect of Upper Airway Surgery on Continuous Positive Airway

Pressure Levels and Adherence: A Systematic Review and Meta-Analysis

\section{References}

1

3 Young T, Shahar E, Nieto FJ, Redline S, Newman AB, Gottlieb DJ, et al: Predictors of sleep-disordered breathing in community-dwelling adults: the Sleep Heart Health Study. Arch Intern Med 2002;162:893-900.

4 Patel SR, White DP, Malhotra A, Stanchina ML, Ayas NT: Continuous positive airway pressure therapy for treating sleepiness in a diverse population with obstructive sleep apnea: results of a meta-analysis. Arch Intern Med 2003;163:565-571.

5 Weaver TE, Maislin G, Dinges DF, Bloxham T, George CF, Greenberg H, et al: Relationship between hours of CPAP use and achieving normal levels of sleepiness and daily functioning. Sleep 2007;30:711-719.

6 Antic NA, Catcheside P, Buchan C, Hensley M, Naughton MT, Rowland S, et al: The effect of CPAP in normalizing daytime sleepiness, quality of life, and neurocognitive function in patients with moderate to severe OSA. Sleep 2011;34:111-119.

7 van Zeller M, Severo M, Santos AC, Drummond M: 5-years APAP adherence in OSA patients - do first impressions matter? Respir Med 2013;107:2046-2052.

8 Zonato AI, Bittencourt LR, Martinho FL, Gregorio LC, Tufik S: Upper airway surgery: the effect on nasal continuous positive airway pressure titration on obstructive sleep apnea patients. Eur Arch Otorhinolaryngol 2006;263:481-486.

9 Chandrashekariah R, Shaman Z, Auckley D: Impact of upper airway surgery on CPAP compliance in difficultto-manage obstructive sleep apnea. Arch Otolaryngol Head Neck Surg 2008;134:926-930.

10 Smith I, Lasserson TJ: Pressure modification for improving usage of continuous positive airway pressure machines in adults with obstructive sleep apnoea. Cochrane Database Syst Rev 2009;4:CD003531.

11 BaHammam AS, Alassiri SS, Al-Adab AH, Alsadhan IM, Altheyab AM, Alrayes AH, et al: Long-term compliance with continuous positive airway pressure in Saudi patients with obstructive sleep apnea. A prospective cohort study. Saudi Med J 2015;36:911-919.

12 Fujita S, Conway W, Zorick F, Roth T: Surgical correction of anatomic abnormalities in obstructive sleep apnea syndrome: uvulopalatopharyngoplasty. Otolaryngol Head Neck Surg 1981;89:923-934.

13 Sher AE, Schechtman KB, Piccirillo JF: The efficacy of surgical modifications of the upper airway in adults with obstructive sleep apnea syndrome. Sleep 1996;19:156-177.

14 Friedman M, Tanyeri H, Lim JW, Landsberg R, Vaidyanathan K, Caldarelli D: Effect of improved nasal breathing on obstructive sleep apnea. Otolaryngol Head Neck Surg 2000;122:71-74.

15 Caples SM, Rowley JA, Prinsell JR, Pallanch JF, Elamin MB, Katz SG, et al: Surgical modifications of the upper airway for obstructive sleep apnea in adults: a systematic review and meta-analysis. Sleep 2010;33:13961407.

16 Friedman M, Soans R, Joseph N, Kakodkar S, Friedman J: The effect of multilevel upper airway surgery on continuous positive airway pressure therapy in obstructive sleep apnea/hypopnea syndrome. Laryngoscope 2009;119:193-196.

17 Khan A, Ramar K, Maddirala S, Friedman O, Pallanch JF, Olson EJ: Uvulopalatopharyngoplasty in the management of obstructive sleep apnea: the Mayo Clinic experience. Mayo Clin Proc 2009;84:795-800.

18 Lin S, Toma R, Glavin C, Toma M, Badr MS, Rowley JA: Tolerance of positive airway pressure following sitespecific surgery of upper airway. Open Sleep J 2008;1:34-39.

19 Nakata S, Noda A, Yagi H, Yanagi E, Mimura T, Okada T, et al: Nasal resistance for determinant factor of nasal surgery in CPAP failure patients with obstructive sleep apnea syndrome. Rhinology 2005;43:296-299.

20 Nakata S, Noda A, Yanagi E, Suzuki K, Yamamoto H, Nakashima T: Tonsil size and body mass index are important factors for efficacy of simple tonsillectomy in obstructive sleep apnoea syndrome. Clin Otolaryngol 2006;31:41-45.

21 Bertoletti F, Indelicato A, Banfi P, Capolunghi B: Sleep apnoea/hypopnoea syndrome: combination therapy with the Pillar palatal implant technique and continuous positive airway pressure (CPAP). A preliminary report. B-ENT 2009;5:251-257.

22 Mortimore IL, Bradley PA, Murray JA, Douglas NJ: Uvulopalatopharyngoplasty may compromise nasal CPAP therapy in sleep apnea syndrome. Am J Respir Crit Care Med 1996;154:1759-1762.

23 Sufioglu M, Ozmen OA, Kasapoglu F, Demir UL, Ursavas A, Erisen L, et al: The efficacy of nasal surgery in obstructive sleep apnea syndrome: a prospective clinical study. Eur Arch Otorhinolaryngol 2012;269:487494.

24 Gillespie MB, Wylie PE, Lee-Chiong T, Rapoport DM: Effect of palatal implants on continuous positive airway pressure and compliance. Otolaryngol Head Neck Surg 2011;144:230-236.

25 Powell NB, Zonato AI, Weaver EM, Li K, Troell R, Riley RW, et al: Radiofrequency treatment of turbinate hypertrophy in subjects using continuous positive airway pressure: a randomized, double-blind, placebo-controlled clinical pilot trial. Laryngoscope 2001;111:1783-1790.

26 Schonhofer B, Kerl J, Suchi S, Kohler D, Franklin KA: Effect of nasal valve dilation on effective CPAP level in obstructive sleep apnea. Respir Med 2003;97:1001-1005.

27 Weaver TE, Grunstein RR: Adherence to continuous positive airway pressure therapy: the challenge to effective treatment. Proc Am Thorac Soc 2008;5:173-178. 